\title{
Proximal humeral fractures
}

\author{
Craig S. Mauro
}

Published online: 2 August 2011

(C) Springer Science+Business Media, LLC 2011

\begin{abstract}
Proximal humeral fractures may present with many different configurations in patients with varying comorbities and expectations. As a result, the treating physician must understand the fracture pattern, the quality of the bone, other patient-related factors, and the expanding range of reconstructive options to achieve the best functional outcome and to minimize complications. Current treatment options range from non-operative treatment with physical therapy to fracture fixation using percutaneous or open techniques to arthroplasty reconstructions. This article reviews the current literature on the classification and treatment options for proximal humeral fractures, while seeking to help the reader to define the most appropriate treatment plan for each individual patient with this type of fracture.
\end{abstract}

Keywords Shoulder Proximal humeral fracture ·

Percutaneous fixation - Open reduction internal fixation . Intramedullary nailing $\cdot$ Hemiarthroplasty $\cdot$ Reverse total shoulder arthroplasty · Avascular necrosis · Nonunion . Malunion $\cdot$ Neer

\section{Introduction}

Proximal humeral fractures account for nearly 5\% of all fractures and are the third most common fracture after hip fractures and distal radial fractures [1]. The majority of these fractures are the result of low energy falls, are minimally

\section{S. Mauro $(\square)$}

Burke and Bradley Orthopedics,

University of Pittsburgh Medical Center,

UPMC St. Margaret 200 Delafield Rd. Suite 4010,

Pittsburgh, PA 15215, USA

e-mail: maurocs@upmc.edu displaced, and may be treated with sling immobilization and physical therapy. However, in approximately $20 \%$ of fractures, surgery should be considered [2]. The treating surgeon must have an understanding of the fracture pattern, the quality of the bone, other patient-related factors, and the expanding range of reconstructive options. The goal of this review is to describe the clinical and radiographic classification systems, clinical decision-making factors, treatment options, outcomes, and complications related to proximal humeral fractures.

\section{Patient assessment}

A careful history is an important component of the assessment, as it important to establish the mechanism of injury to help to define the "personality" of the fracture. Further, it is imperative that concomitant injuries, such as head injuries, are identified and treated. Information about the patient's pre-trauma shoulder function and other comorbidities are important considerations in the fracture management.

The physical examination is used to identify skin or neurovascular damage. Although open fractures of the proximal humerus are rare, displaced fractures may cause extensive ecchymosis, swelling, skin tenting, or pressure necrosis. Neurologic or vascular injuries are most common in the setting of fracture-dislocations. They must be identified expeditiously, documented, and treated appropriately, often in conjunction with other specialists such as vascular surgeons and/or interventional radiologists.

Standard radiographs of the shoulder, including an anterior-posterior view, a trans-scapular view, and an axillary view, should be obtained on all patients with a suspected shoulder fracture. In the majority of cases, these 
plain radiographs are sufficient to define the fracture pattern. Computed tomography (CT) can be used to evaluate for a head-splitting component, better define the bone quality or the degree of comminution, and to further delineate the fracture configuration. Full-length views of the affected and contralateral humeri may be useful for templating if arthroplasty is being considered.

\section{Radiological classification}

The fracture pattern is an important consideration when deciding upon treatment for and predicting the risk of osteonecrosis after proximal humeral fractures. The Neer [2] and the AO/ASIF [3] classifications are the most commonly employed classification systems. With the Neer classification, the fracture patterns are differentiated by the number of fragments, the direction of dislocation, and the involvement of the articular surface. To be considered a fragment, the fracture part must be displaced $>1 \mathrm{~cm}$ or must be angulated $>45^{\circ}$. The AO/ASIF classifies fractures based on the severity of the injury and likelihood of avascular necrosis of the humeral head. However, some studies have demonstrated low inter-observer reliability for the Neer and AO/ASIF systems [4, 5].

More recently, Hertel et al. devised a binary (LEGO) system for proximal humeral fractures [6]. They utilized this system, which corresponds to the four-part system but provides more description, and correlated it to humeral head perfusion, which was assessed intra-operatively. They found that the most relevant predictors of ischemia were the length of the dorsomedial metaphyseal extension, the integrity of the medial hinge, and the basic fracture type determined with the binary description system.

\section{Treatment}

Although the fracture pattern is an important consideration when deciding upon treatment for and predicting the risk of osteonecrosis after proximal humeral fractures, other patient-related factors contribute to the personality of the fracture. These factors, as well as surgeon expertise, must also be considered when determining treatment. In a recent review, Murray et al. outlined the patient-related factors which they consider to be most significant in contributing to the personality of the fracture [7]. The factors that they consider to be relative indications for non-operative treatment include benign fracture configurations, frail, elderly patients, and those patients with co-morbidities such as severe osteoporosis, smoking, drug and alcohol abuse, diabetes mellitus, rheumatoid arthritis, and immunocompromised states. Other fractures fall into one of three groups: fractures in which surgery is essential, fractures which may benefit from reduction and fixation, and fractures which may benefit from arthroplasty.

The rare cases for which surgery for proximal humeral fractures is essential include cases of open fractures, an associated vascular injury, and pathologic fractures. Threeand four-part fracture-dislocations and head splitting fractures are very strong indications for surgery as well, but all patient characteristics must be considered before operating in all patients.

Fractures which may benefit from reduction and fixation are those in which operative treatment can be expected to improve the outcome compared to non-operative treatment. Murray et al. [7] outlined their recommendations for fractures in which reduction and fixation should be considered:

1. Two-part greater or lesser tuberosity fractures, or threeand/or four-part fractures in which the greater tuberosity is displaced by more than $1 \mathrm{~cm}$.

2. Fractures with a displaced fragment of the articular surface of the humeral head attached to a displaced tuberosity fragment.

3. Unstable two-part surgical neck fractures in which there is disengagement of the shaft from the humeral head, due to displacement or extensive metaphyseal comminution.

4. Two-, three- or four-part fractures in which there is varus or valgus deformity of the humeral head to the shaft by $>30^{\circ}$ from the normal head shaft inclination angle of $130^{\circ}$.

5. Three- or four-part anterior fracture-dislocations caused by propagation of a posterior humeral head fracture ('Hill-Sachs lesion') and with retained soft-tissue attachments to the humeral head at surgery ('Type 1' anterior fracture-dislocation).

6. Three- or four-part posterior fracture-dislocations caused by propagation of a fracture of the anterior humeral head ('reverse Hill-Sachs') and with retained soft-tissue attachments to the humeral head at surgery.

Arthroplasty in the form of humeral head hemiarthroplasty or reverse total shoulder arthroplasty may be considered in patients with appropriate fracture patterns in whom reduction and fixation is ill-advised, who are medically stable, can tolerate extensive surgery, and who are able to participate in the prescribed postoperative rehabilitation program. Voos et al. [8] described their general indications for hemiarthroplasty for proximal humeral fractures to include: displaced three- and four-part fractures, age $>70$ years, severe osteoporosis, humeral head osteonecrosis, failure to maintain open reduction and internal fixation, head-splitting fracture, and fracture-dislocation. They also defined their indications for reverse total shoulder age $>70$ years combined with low 
demands, a fracture with severe tuberosity and metaphyseal comminution, severe osteoporosis, cuff tear arthropathy, fatty infiltration of a massive rotator cuff tear, a failed hemiarthroplasty, and comorbidities that would affect tuberosity healing.

\section{Treatment options}

Non-operative

The advantages of non-operative treatment of appropriately selected proximal humeral fractures are the minimal risk of infection and operative complications with similar functional outcomes to operatively treated fractures. Outcomes are improved if supervised physical therapy is started earlier and immobilization is minimized $[9,10]$. However, functional outcome is worse in cases of nonunion, symptomatic malunion, or avascular necrosis [7, 11, 12]. This finding, in addition to the observation of worse outcomes with secondary surgery than with primary operative treatment [13], has helped to define the previously described indications for primary operative treatment.

\section{Reduction and percutaneous fixation}

Minimally invasive reduction and percutaneous fixation techniques include Kirschner (K-) wire, screw fixation, Humerus Block (Synthes, Bettlach, Switzerland), or combination techniques. The advantage of these minimally invasive techniques is that they require less dissection and, potentially, less disruption of the vascular supply to the humeral head than do traditional open techniques. Resch et al. have popularized a technique for percutaneous reduction and fixation of proximal humeral fractures, including three and four part fractures (Fig. 1) [14-17]. This Humerus Block technique utilizes a metal block that is fixed to the humeral shaft by a cannulated cortical screw. The shaft is brought into alignment with the humeral head with axial traction under image intensifier guidance. Through a small incision, an elevator is used to reduce the head fragment. Two crossed K-wires are passed through the block at an angle of $45^{\circ}$ and into the head fragment. K-wires and cannulated screws are then used to percutaneously reduce and fix the greater and/or lesser tuberosity fragments. This implant construct seeks to take advantage of the features of semi-rigidity and controlled impaction [15]. In this controlled impaction philosophy, the implant is a guiding tool rather than a rigid fixation device and allows for impaction of the humeral head.

Bogner et al. [14] published the results of a series of 51 patients with three- and four-part proximal humeral frac-

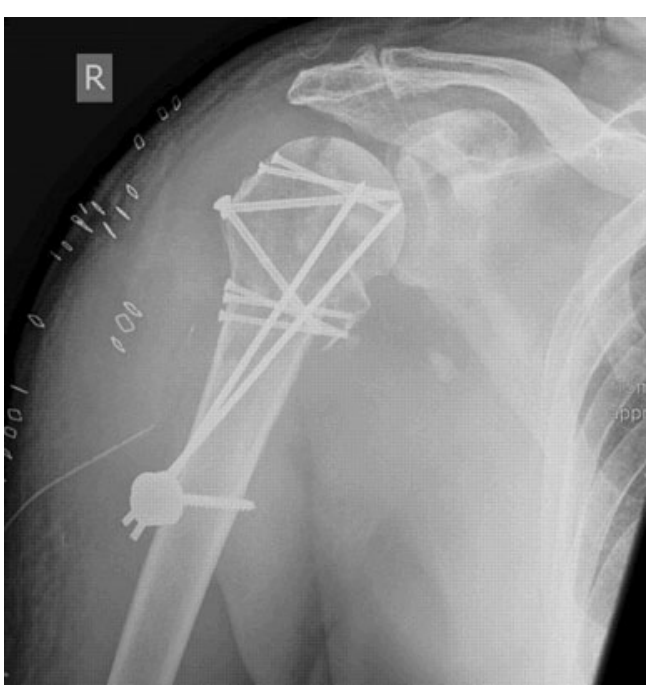

Fig. 1 A four-part proximal humeral fracture treated with percutaneous reduction and fixation using the Humerus Block technique

tures treated with percutaneous fixation and reduction using the Humerus Block implant. Of the 51 fractures, three hemiarthroplasties $(5.9 \%)$ were performed subsequent to the Humerus Block; two were performed because of fragment dislocation and one because of avascular necrosis of the humeral head. Of the remaining 48 fractures, the mean Constant score at follow-up was 61 in the 32 with a three-part fracture and 50 in four-part fractures. Ninety percent healed primarily, while secondary displacement of fragments or migration of the K-wires was seen in $10 \%$. Brunner et al. [18] also reported on the outcomes of 58 patients treated with the Humerus Block technique, noting a Constant score of 74 , but requiring an unplanned reoperation rate of $40 \%$.

Keener et al. [19] followed 27 patients who were treated with closed or percutaneous reduction and percutaneous fixation of displaced two-, three-, and four-part proximal humeral fractures. They found that all fractures healed after the index procedure and the mean ASES score was 83 and the mean Constant score was 74 . Fenichel et al. [20] reviewed the outcomes of 50 patients with proximal humeral fractures treated with closed reduction and percutaneous pinning using threaded pins. They found that the average Constant score was 81 , while fractures confined to the surgical or anatomical neck generally did better than those associated with a greater tuberosity fragment.

\section{Open reduction and internal fixation}

Open reduction and internal fixation (ORIF) provides the features of anatomical fracture reduction, rigid fixation, and the possibility of bone grafting. However, as compared to minimally invasive techniques, there may be a higher risk 
of infection and avascular necrosis with ORIF. Further, adequate screw purchase with standard internal fixation requires a cortical thickness of $>4 \mathrm{~mm}$ [21]. A standard deltopectoral approach has commonly been used for this fixation technique. Recently, straight lateral [22] and shoulder strap [23] approaches have been described for use in this setting. These approaches require identification and protection of the axillary nerve, but improve access to the lateral aspect of the proximal humerus for fracture reduction and plate positioning.

The technique for ORIF in the presence of multiple fragments generally involves first identifying the fragments and the rotator cuff tendons. K-wires, elevators, and/or osteotomes are then used to gently manipulate the head fragment. A lateral plate can then be used to correct the translation of the medial shaft and reduce and fix the fragments into the anatomic position [7, 24]. In cases where there is a significant metaphyseal bone defect, the defect may be filled with local bone graft or bone-graft substitute [25]. Alternatively, an allograft strut may be used to support the medial column, especially in cases of varus instability [26].

There have been several recent studies which have demonstrated satisfactory outcomes following ORIF of proximal humeral fractures [25, 27-32]. Brunner et al. [27] treated 158 fractures and at 1 year follow up noted a Constant score of 72 . They found screw perforation to be the most common complication (22\%) and reported an $8 \%$ rate of avascular necrosis. Sudkamp et al. [29] followed 187 patients treated with ORIF using a locking proximal humeral plate. vAt one year, they found a mean Constant score of 71 and a $14 \%$ rate of screw perforation. Solberg et al. [28] found better clinical outcomes in older patients with three- and four-part proximal humeral fractures with initial valgus angulation (compared to those with initial varus angulation) and a metaphyseal segment attached to the articular fragment of greater than $2 \mathrm{~mm}$. Robinson et al. [25] treated 47 patients with a proximal humeral fracture in which there was a severe varus deformity. They used a standard operative protocol of anatomical reduction, fixation with a locking plate, and supplementation by structural allografts in unstable fractures and found a median Constant score of 86 at 2 years post-operatively.

\section{Intramedullary nail}

Intramedullary nails may provide stable fixation for proximal humeral fractures and require minimal soft tissue dissection for insertion. They are especially suited for two-part surgical neck fractures, as three- and four-part fractures are not generally amenable to reduction and fixation with an intramedullary device. The technique involves closed or percutaneous reduction of the fracture, a deltoid splitting approach to the humeral head, and antegrade insertion of the intramedullary nail. As a result of this starting point, the rotator cuff insertion may be damaged with this technique, leading to pain, stiffness, and shoulder dysfunction. Reports of intramedullary nailing of proximal humeral fractures have generally demonstrated satisfactory outcomes in patients with two-part fractures, but less reliable outcomes in patients with three- and four-part fractures [33-38]. One recent report found no differences in the functional outcome of proximal humeral fractures treated with either a plate or an antegrade nail [39].

\section{Arthroplasty}

Arthroplasty is an important treatment option for proximal humeral fractures in which there is a severe, head-splitting component, particularly in the case of an older patient with poor bone quality. Hemiarthroplasty has generally been the arthroplasty procedure of choice for acute fractures, with the goals being to restore the tuberosities to the anatomic position and to achieve the appropriate head component height, off-set, and version [8, 40]. The outcomes of hemiarthroplasty in lower-demand, elderly patients, especially in the setting of tuberosity comminution, cuff tear arthropathy, or a massive rotator cuff tear with fatty infiltration, have led to the popularity of the reverse shoulder arthroplasty in this situation. Specifically, it is an attractive option because of the ability of the prosthesis to compensate for tuberosity dysfunction. Further, the reverse total shoulder arthroplasty may also be used in the setting of a proximal humeral malunion or a failed hemiarthroplasty for proximal humeral fracture [41-43].

The technique for humeral head hemiarthroplasty for treatment of a proximal humeral fracture has been well described and generally follows the principles outline by Neer [8, 44, 45]. A standard deltopectoral approach is utilized, the tuberosities are identified and protected for later reconstruction, and the remaining head fragments are removed. The humeral canal is prepared and the humeral component is trialed and implanted, ensuring appropriate height, head size, offset, and version. Restoration and healing of the tuberosities has been shown to be the most critical portion of the reconstruction and, as such, much has been written about improving techniques to promote stability and tuberosity healing [8, 44, 46-50]. The techniques involve suturing the tuberosities to each other and to the prosthesis, with some incorporating cerclage with cable or suture and/or bone grafting. A reverse shoulder arthroplasty for treatment of a proximal humeral fracture may be performed through a superolateral or deltopectoral approach [51]. The principles of fracture 
exposure, proper implant positioning, and tuberosity reattachment outlined for hemiarthroplasty hold true for reverse arthroplasty as well.

Robinson et al. [52] reviewed the outcomes of 138 patients treated with hemiarthroplasty for a proximal humeral fracture. They found the best functional outcome in younger patients with no preoperative neurological deficit, no postoperative complications, and a satisfactory radiographic appearance of the shoulder at six weeks. Poorer results were noted in elderly patients, particularly in those with a neurological deficit, a postoperative complication requiring a reoperation, or an eccentrically located prosthesis with retracted tuberosities.

In a multicenter study of 167 patients who had a hemiarthroplasty for three- and four-part fractures, Kralinger et al. [53] noted anatomical healing of the tuberosity significantly influenced the outcome as measured by the Constant score and subjective patient satisfaction. This finding was corroborated by another multicenter analysis on the functional outcome of shoulder hemiarthroplasty for fractures [54]. A recent systematic review of the literature examining the role of hemiarthroplasty in the early management of proximal humeral fractures found a mean Constant score of 57 [55]. No pain or only mild pain was experienced by most patients, but marked limitation of function persisted. Complications related to the fixation and healing of the tuberosities were observed in $11 \%$ of cases.

The outcome reports of reverse shoulder arthroplasty for treatment of proximal humeral fractures have been more limited in number [56-60]. Bufquin et al. [57] reported on the short term (mean 22 months) outcomes of 43 patients, noting mean active anterior elevation of $97^{\circ}$ and mean active external rotation in abduction of $30^{\circ}$. They concluded that these outcomes demonstrated satisfactory mobility despite frequent $(53 \%)$ migration of the tuberosities. Cazeneuve et al. [60] reported the clinical and radiological outcome at a mean of 6.6 years for 36 fractures treated with reverse total shoulder arthroplasty. They found a Constant score of 53 and noted that $63 \%$ of patients had radiological evidence of loosening of the glenoid component. However, only one patient had aseptic loosening of the baseplate at 12 years' follow-up.

\section{Complications}

The complications of proximal humeral fractures may occur as a result of the injury, or secondary to operative treatment. Several have been previously discussed and they most commonly are related to avascular necrosis and/or tuberosity malunion. Complications most commonly associated with non-operative treatment are avascular necrosis and symptomatic malunion $[11,12,61]$. While operative treatment methods seek to reduce the incidence of malunion, they introduce the complications of infection, iatrogenic neurologic or vascular injury, and hardware migration and failure $[14,21,27,29]$. Arthroplasty is indicated in severe cases where rates of avascular necrosis are high and fracture fixation is ill-advised, but it brings its own set of challenges and complications. Tuberosity malunion or nonunion, leading to rotator cuff dysfunction, is a primary complication leading to poor outcomes [46]. However, component malposition, instability, heterotopic ossification, periprosthetic fracture, glenoid erosion, infection, and nerve injury are not uncommon after hemiarthroplasty for proximal humeral fracture [12, 40, 55]. With reverse total shoulder arthroplasty, the complication list also includes scapular notching and glenoid loosening $[51,57,60]$.

\section{Conclusions}

Proximal humeral fractures may have many different personalities and the treating surgeon must understand the fracture pattern, the quality of the bone, other patientrelated factors, and the expanding range of reconstructive options. Appropriate application of non-operative treatment with physical therapy, fracture fixation using percutaneous or open techniques, and hemiarthroplasty or reverse shoulder arthroplasty allows for the best functional patient outcome while minimizing complications.

Disclosure No potential conflict of interest relevant to this article was reported.

\section{References}

Papers of particular interest, published recently, have been highlighted as:

- Of importance

1. Court-Brown CM, Caesar B. Epidemiology of adult fractures: A review. Injury. 2006;37:691-7.

2. Neer 2nd CS. Displaced proximal humeral fractures. I. Classification and evaluation. J Bone Joint Surg Am. 1970;52:1077-89.

3. Müller ME. Appendix A: the comprehensive classification of fractures of long bones. In: Müller ME, Allgöwer M, Schneider R, Willenegger $\mathrm{H}$, editors. Manual of Internal Fixation: Techniques Recommended by the AO-ASIF Group. Berlin: Springer; 1991. p. 118-25.

4. Sidor ML, Zuckerman JD, Lyon T, et al. The Neer classification system for proximal humeral fractures. An assessment of interobserver reliability and intraobserver reproducibility. J Bone Joint Surg Am. 1993; 75:1745-50.

5. Siebenrock KA, Gerber C. The reproducibility of classification of fractures of the proximal end of the humerus. J Bone Joint Surg Am. 1993;75:1751-5. 
6. Hertel R, Hempfing A, Stiehler M, Leunig M. Predictors of humeral head ischemia after intracapsular fracture of the proximal humerus. J Shoulder Elbow Surg. 2004;13:427-33.

7. Murray IR, Amin AK, White TO, Robinson CM. Proximal humeral fractures: current concepts in classification, treatment and outcomes. J Bone Joint Surg Br. 2011;93:1-11.

8. Voos JE, Dines JS, Dines DM. Arthroplasty for fractures of the proximal part of the humerus. J Bone Joint Surg Am. 2010;92:1560-7.

9. Koval KJ, Gallagher MA, Marsicano JG, et al. Functional outcome after minimally displaced fractures of the proximal part of the humerus. J Bone Joint Surg Am. 1997;79:203-7.

10. Kristiansen B, Angermann P, Larsen TK. Functional results following fractures of the proximal humerus. A controlled clinical study comparing two periods of immobilization. Arch Orthop Trauma Surg. 1989;108:339-41.

11. Poeze M, Lenssen AF, Van Empel JM, Verbruggen JP. Conservative management of proximal humeral fractures: can poor functional outcome be related to standard transscapular radiographic evaluation? J Shoulder Elbow Surg. 2010;19:273-81.

12. Tejwani NC, Liporace F, Walsh M, et al. Functional outcome following one-part proximal humeral fractures: a prospective study. J Shoulder Elbow Surg. 2008;17:216-9.

13. Bosch U, Skutek M, Fremerey RW, Tscherne H. Outcome after primary and secondary hemiarthroplasty in elderly patients with fractures of the proximal humerus. J Shoulder Elbow Surg. 1998;7:479-84.

14. Bogner R, Hubner C, Matis N, et al. Minimally-invasive treatment of three- and four-part fractures of the proximal humerus in elderly patients. J Bone Joint Surg Br. 2008;90:1602-7.

15. Resch H. Proximal humeral fractures: current controversies. J Shoulder Elbow Surg. 2011; In press.

16. Resch H, Hubner C, Schwaiger R. Minimally invasive reduction and osteosynthesis of articular fractures of the humeral head. Injury. 2001;32 Suppl 1:SA25-32.

17. Resch H, Povacz P, Frohlich R, Wambacher M. Percutaneous fixation of three- and four-part fractures of the proximal humerus. J Bone Joint Surg Br. 1997;79:295-300.

18. Brunner A, Weller K, Thormann S, et al. Closed reduction and minimally invasive percutaneous fixation of proximal humerus fractures using the Humerusblock. J Orthop Trauma. 2010;24:407-13.

19. Keener JD, Parsons BO, Flatow EL, et al. Outcomes after percutaneous reduction and fixation of proximal humeral fractures. J Shoulder Elbow Surg. 2007;16:330-8.

20. Fenichel I, Oran A, Burstein G, Perry Pritsch M. Percutaneous pinning using threaded pins as a treatment option for unstable two- and three-part fractures of the proximal humerus: a retrospective study. Int Orthop. 2006;30:153-7.

21. Nho SJ, Brophy RH, Barker JU, et al. Management of proximal humeral fractures based on current literature. J Bone Joint Surg Am. 2007;89 Suppl 3:44-58.

22. Gardner MJ, Boraiah S, Helfet DL, Lorich DG. The anterolateral acromial approach for fractures of the proximal humerus. J Orthop Trauma. 2008;22:132-7.

23. Robinson CM, Khan L, Akhtar A, Whittaker R. The extended deltoid-splitting approach to the proximal humerus. J Orthop Trauma. 2007;21:657-62.

24. Konrad G, Bayer J, Hepp P, et al. Open reduction and internal fixation of proximal humeral fractures with use of the locking proximal humerus plate. Surgical technique. J Bone Joint Surg Am. 2010;92(Suppl 1 Pt):85-95.

25. Robinson CM, Wylie JR, Ray AG, et al. Proximal humeral fractures with a severe varus deformity treated by fixation with a locking plate. J Bone Joint Surg Br. 2010;92:672-8.

26. Gardner MJ, Boraiah S, Helfet DL, Lorich DG. Indirect medial reduction and strut support of proximal humerus fractures using an endosteal implant. J Orthop Trauma. 2008;22:195-200.
27. - Brunner F, Sommer C, Bahrs C, et al. Open reduction and internal fixation of proximal humerus fractures using a proximal humeral locked plate: a prospective multicenter analysis. J Orthop Trauma. 2009;23:163-72. Open reduction and internal fixation leads to good functional outcomes, but a high rate of complications may be experienced.

28. Solberg BD, Moon CN, Franco DP, Paiement GD. Locked plating of 3- and 4-part proximal humerus fractures in older patients: the effect of initial fracture pattern on outcome. J Orthop Trauma. 2009;23:113-9.

29. Sudkamp N, Bayer J, Hepp P, et al. Open reduction and internal fixation of proximal humeral fractures with use of the locking proximal humerus plate. Results of a prospective, multicenter, observational study. J Bone Joint Surg Am. 2009;91:1320-8.

30. Bigorre N, Talha A, Cronier P, et al. A prospective study of a new locking plate for proximal humeral fracture. Injury. 2009;40:1926.

31. Geiger EV, Maier M, Kelm A, et al. Functional outcome and complications following PHILOS plate fixation in proximal humeral fractures. Acta Orthop Traumatol Turc. 2010;44:1-6.

32. Duralde XA, Leddy LR. The results of ORIF of displaced unstable proximal humeral fractures using a locking plate. J Shoulder Elbow Surg. 2010;19:480-8.

33. Adedapo AO, Ikpeme JO. The results of internal fixation of threeand four-part proximal humeral fractures with the Polarus nail. Injury. 2001;32:115-21.

34. Agel J, Jones CB, Sanzone AG, et al. Treatment of proximal humeral fractures with Polarus nail fixation. J Shoulder Elbow Surg. 2004;13:191-5.

35. Georgousis M, Kontogeorgakos V, Kourkouvelas S, et al. Internal fixation of proximal humerus fractures with the polarus intramedullary nail. Acta Orthop Belg. 2010;76:462-7.

36. Rajasekhar C, Ray PS, Bhamra MS. Fixation of proximal humeral fractures with the Polarus nail. J Shoulder Elbow Surg. 2001;10:7-10.

37. Iacobellis C, Serafini D, Aldegheri R. PHN for treatment of proximal humerus fractures: evaluation of 80 cases. Chir Organi Mov. 2009;93:47-56.

38. Kazakos K, Lyras DN, Galanis V, et al. Internal fixation of proximal humerus fractures using the Polarus intramedullary nail. Arch Orthop Trauma Surg. 2007;127:503-8.

39. Gradl G, Dietze A, Kaab M, et al. Is locking nailing of humeral head fractures superior to locking plate fixation? Clin Orthop Relat Res. 2009;467:2986-93.

40. Krishnan SG, Bennion PW, Reineck JR, Burkhead WZ. Hemiarthroplasty for proximal humeral fracture: restoration of the Gothic arch. Orthop Clin North Am. 2008;39:441-50. vi.

41. Levy J, Frankle M, Mighell M, Pupello D. The use of the reverse shoulder prosthesis for the treatment of failed hemiarthroplasty for proximal humeral fracture. J Bone Joint Surg Am. 2007;89:292-300.

42. Willis M, Min W, Brooks J, et al. Proximal humeral malunion treated with reverse shoulder arthroplasty. J Shoulder Elbow Surg. 2011; In press.

43. Martin TG, Iannotti JP. Reverse total shoulder arthroplasty for acute fractures and failed management after proximal humeral fractures. Orthop Clin North Am. 2008;39:451-7. vi.

44. Dines DM, Warren RF. Modular shoulder hemiarthroplasty for acute fractures. Surgical considerations. Clin Orthop Relat Res. $1994 ; 18-26$.

45. Neer 2nd CS. Displaced proximal humeral fractures. II. Treatment of three-part and four-part displacement. J Bone Joint Surg Am. 1970;52:1090-103

46. Boileau P, Krishnan SG, Tinsi L, et al. Tuberosity malposition and migration: reasons for poor outcomes after hemiarthroplasty for displaced fractures of the proximal humerus. J Shoulder Elbow Surg. 2002;11:401-12. 
47. Frankle MA, Ondrovic LE, Markee BA, et al. Stability of tuberosity reattachment in proximal humeral hemiarthroplasty. J Shoulder Elbow Surg. 2002;11:413-20.

48. Abu-Rajab RB, Stansfield BW, Nunn T, et al. Re-attachment of the tuberosities of the humerus following hemiarthroplasty for fourpart fracture. J Bone Joint Surg Br. 2006;88:1539-44.

49. Krause FG, Huebschle L, Hertel R. Reattachment of the tuberosities with cable wires and bone graft in hemiarthroplasties done for proximal humeral fractures with cable wire and bone graft: 58 patients with a 22-month minimum follow-up. J Orthop Trauma. 2007;21:682-6.

50. Dines DM, Warren RF, Altchek DW, Moeckel BH. Posttraumatic changes of the proximal humerus: Malunion, nonunion, and osteonecrosis.Treatment with modular hemiarthroplasty or total shoulder arthroplasty. J Shoulder Elbow Surg. 1993;2:11-21.

51. Sirveaux F, Navez G, Roche O, et al. Reverse prosthesis for proximal humerus fracture, technique and results. Tech Shoulder Elbow Surg. 2008;9:15-22.

52. Robinson CM, Page RS, Hill RM, et al. Primary hemiarthroplasty for treatment of proximal humeral fractures. J Bone Joint Surg Am. 2003;85-A:1215-23.

53. Kralinger F, Schwaiger R, Wambacher M, et al. Outcome after primary hemiarthroplasty for fracture of the head of the humerus. A retrospective multicentre study of 167 patients. J Bone Joint Surg Br. 2004;86:217-9.

54. Reuther F, Muhlhausler B, Wahl D, Nijs S. Functional outcome of shoulder hemiarthroplasty for fractures: A multicentre analysis. Injury. 2010;41:606-12.
55. Kontakis G, Koutras C, Tosounidis T, Giannoudis P. Early management of proximal humeral fractures with hemiarthroplasty: a systematic review. J Bone Joint Surg Br. 2008;90:1407-13.

56. Klein M, Juschka M, Hinkenjann B, et al. Treatment of comminuted fractures of the proximal humerus in elderly patients with the Delta III reverse shoulder prosthesis. J Orthop Trauma. 2008;22:698-704.

57. Bufquin T, Hersan A, Hubert L, Massin P. Reverse shoulder arthroplasty for the treatment of three- and four-part fractures of the proximal humerus in the elderly: a prospective review of 43 cases with a short-term follow-up. J Bone Joint Surg Br. 2007;89:516-20.

58. Boileau P, Watkinson D, Hatzidakis AM, Hovorka I. Neer Award 2005: The Grammont reverse shoulder prosthesis: results in cuff tear arthritis, fracture sequelae, and revision arthroplasty. J Shoulder Elbow Surg. 2006;15:527-40.

59. Cazeneuve JF, Cristofari DJ. Grammont reversed prosthesis for acute complex fracture of the proximal humerus in an elderly population with 5 to 12 years follow-up. Rev Chir Orthop Reparatrice Appar Mot. 2006;92:543-8.

60. - Cazeneuve JF, Cristofari DJ. The reverse shoulder prosthesis in the treatment of fractures of the proximal humerus in the elderly. $\mathrm{J}$ Bone Joint Surg Br. 2010;92:535-9. This report presents the first long-term outcome of the use of reverse shoulder arthroplasty in the treatment of acute complex proximal humeral fractures in the elderly.

61. Hanson B, Neidenbach P, de Boer P, Stengel D. Functional outcomes after nonoperative management of fractures of the proximal humerus. J Shoulder Elbow Surg. 2009;18:612-21. 